\title{
Brazilian Green Propolis Compared to Miconazole Gel in the Treatment of Candida-Associated Denture Stomatitis
}

\author{
Hermínia Marques Capistrano, ${ }^{1}$ Eliene Magda de Assis, ${ }^{2}$ Rosana Maria Leal, ${ }^{1}$ \\ Maria Eugênia Alvarez-Leite, ${ }^{3}$ Sylvie Brener, ${ }^{2}$ and Esther Margarida Alves Ferreira Bastos ${ }^{4}$ \\ ${ }^{1}$ Oral Pathology Laboratory and Stomatology, Dentistry Department, Pontifícia Universidade Católica de Minas Gerais, \\ Dom José Gaspar Avenida, 500, 30535-901 Belo Horizonte, MG, Brazil \\ ${ }^{2}$ DDS Private Practice in Dentistry, Brazil \\ ${ }^{3}$ Microbiology Laboratory, Dentistry Departament, Pontifícia Universidade Católica de Minas Gerais, Brazil \\ ${ }^{4}$ Researcher of FUNED (Fundação Ezequiel Dias) of Minas Gerais, Brazil
}

Correspondence should be addressed to Hermínia Marques Capistrano; herminialau@uol.com.br

Received 3 December 2012; Accepted 3 April 2013

Academic Editor: Zenon Czuba

Copyright (c) 2013 Hermínia Marques Capistrano et al. This is an open access article distributed under the Creative Commons Attribution License, which permits unrestricted use, distribution, and reproduction in any medium, provided the original work is properly cited.

\begin{abstract}
Aim. To evaluate the efficacy of Brazilian green propolis in comparison to miconazole gel in the treatment of Candida-associated denture stomatitis. Methods. Forty-five denture stomatitis patients, with palatal mucosa erythema levels classified according to Newtons's criteria and with positive culture to Candida spp., were randomly divided into three treatment groups: 15 received miconazole gel 2\%, 15 received propolis gel 2,5\%, and 15 received propolis $24 \%$ for mouthwash. After four daily use lasting two weeks, they were reexamined for the denture stomatitis degree and for a second culture of Candida. The Wilcoxon's test was applied to compare the results of clinical classification of the denture stomatitis and the Candida spp. colonies numbers, before and after each treatment. The Kruskall-Wallis's test was used to compare efficacy among the three treatment groups. Results. There were a significant reduction or complete remission of denture stomatitis $(P<0.05)$ and a significant decrease of Candida colonies for the three groups $(P<0.05)$. There was no difference in the efficacy among the treatment groups $(P>0.05)$. Conclusion. Brazilian green propolis has a similar effect as miconazole in the treatment of Candida-associated denture stomatitis being an alternative in the therapeutics of this condition.
\end{abstract}

\section{Introduction}

Denture stomatitis is a common inflammatory lesion in the palatal mucosa of denture wearers who presenting a erythema of variable intensity and extension. Prevalence studies varying between $10 \%$ and more than $65 \%[1,2]$. This etiology is multifactorial involving predisposing factors, for example, denture stability, oral and denture hygiene, lasting use, systemic factors like immunologic and endocrinal diseases, nutritional deficiency, and some medications including corticoids, antibiotics, and immunossupressors [3, 4]. An association between denture stomatitis and Candida spp., specially Candida albicans, has been reported [2, 5-7].

The treatment for denture stomatitis includes meticulous denture hygiene and the reduction of local and general predisposing factors. The association of these procedures with topic antifungal therapy showed good results in the reduction of the palatal mucosa inflammation and decreasing of yeast number of Candida spp. in the palate and in denture fitting $[2,8,9]$. The most common synthetic drugs used are imidazole related compounds such as miconazole, polyenic derivatives such as nystatin and others $[2,3,5,10]$.

Miconazole is an antifungal for topical oral administration and has been showing a good effect in therapeutic or prophylactic treatment of Candida-associated denture stomatitis, reducing erythema $[2,11]$, and decreasing colonies of Candida spp. [2,5].

Propolis is a resinous material collect by bees from various plants, and this chemical composition depends on its origin area [12-14]. Propolis has been used as 
an anti-inflammatory purpose in folk medicine since early times especially in Europe [13]. Extract of propolis contains a wide variety of components like flavonoids and phenolic acids. The flavonoids in propolis, mainly pinocembrin, have been considered to be responsible for its inhibitory effect on Candida [15], but only traces of these compounds have been found in propolis of South American origin [16], indicating that this effect could be due to a different class of compounds such as the high content of aromatic acids and possibly the presence of amyrins [17] that is known to possess several therapeutical activities $[18,19]$.

Several new compounds have already been identified in Brazilian green propolis samples [20, 21], and studies have attesting its biological effects like microbicidal, antiinflammatory, antioxidative, anticancer, and cytotoxic activities and their therapeutics uses $[13,16,18,22,23]$. Antifungal activity is one of the most extensively investigated biological actions of propolis [22]. Thus, the aim of this study was the comparison of the efficacy of a new form of Brazilian green propolis, using a formula propylene glycol contrasting it with miconazole gel in the topical treatment of Candida-associated denture stomatitis.

\section{Material and Methods}

This study was approved by Ethics Committee of the Pontificia Universidade Catolica de Minas Gerais (CEP/PUCMinas, protocol number: CEP 0022.0.213.000-05. Address: Avenida Dom José Gaspar 500, Dom Cabral-Belo Horizonte, MG, Brazil; June 9th, 2005). All participants were informed about the study objectives and signed a declaration of informed consent before the start of the study.

2.1. Subject Selection and Samples Collection. At baseline, eighty denture wearers individuals, presenting clinical denture stomatitis, were selected randomly among patients of the Pathology Clinic of a Dentistry School (Departamento de Odontologia da Pontificia Universidade Católica de Minas Gerais (DOPUC) Minas), Brazil. Thirty more subjects with normal palatal mucosa (15 denture users and 15 having natural teeth) were also selected to compare the count of colony-forming units (CFUs) of Candida spp. among subjects with and without denture stomatitis.

Patient inclusion criteria were (1) denture stomatitis covered the palatal mucosa; (2) diagnosed candidiasis confirmed by microbiologic cultures from the erythematous palatal mucosa of the denture wearers. The exclusion criteria were as follows: (1) no patient user of antimycotics, antibiotics, or anti-inflammatory during 2 months before selection; (2) no medication that caused hyposalivation or xerostomia. Swabs were used to collect yeast samples from the denture underlying palatal mucosa of the 110 individuals, with $(n=$ $80)$ and without $(n=30)$ denture stomatitis. Swabs were plated onto Sabouraud dextrose agar (Difco) containing chloramphenicol $(100 \mathrm{mg} / \mathrm{L})$ and incubated aerobically at $28^{\circ} \mathrm{C}$. Isolation and identification of the species were performed after 48 hours of incubation. Before isolation, the number of CFUs was determined, and morphological characteristics were observed. All isolates were identified with the aid of a germ-tube test (Reynolds-Braude effect) with positive test and presumptive diagnose of Candida albicans.

\subsection{Study Groups, Data Collection and Clinical Evaluation.} Out of 85 patients with clinical presentation of denture stomatitis, only 45 had Candida spp. positive microbiological tests, and these patients were included in the study group. All individuals with health palatal mucosa either denture users or with natural teeth $(n=30)$ had no yeast colony growth in culture.

At start, personal data and medical history of the 45 individuals of the study groups were obtained. Patients were inquired about habits like sleeping with denture, age of dentures, last change of the prosthesis, and how their denture hygiene was done. All of them had instructions about denture hygiene. Clinical examination and smears of palatal mucosa for culture were made by only one examiner, an oral pathologist following the biosafety norms. The palatal mucosa erythema levels were classified according to Newtons's criteria [24], and photographs of their palatal mucosa were taken by the same examiner.

The patients were randomically allocated in three parallel treatment groups. Group I was treated with topical use miconazole gel $2 \%(n=15$; mean age $62.5 \pm 13.5$ years; 3 men and 12 women). Group II was treated with topical use propylene glycol Brazilian green propolis gel 2.5\% ( $n=15$; mean age $57.7 \pm 13.2$ years; 2 man and 13 women). Group III received propylene glycol Brazilian green propolis $24 \%$, in form of mouthwash $(n=15$; mean age $62.0 \pm 5.5$ years; 2 men and 13 women). The propylene glycol extract of Brazilian green propolis used in two different groups had the objective of testing its most efficient and best-tasting form, gel or mouthwash, once this is a pilot study.

2.3. Treatment Posology. The standard protocol used for the three groups included previous hygiene of denture. Following, patients of the Groups I and II applied miconazole gel and propolis gel, respectively, (5 $\mathrm{mL}$ or one teaspoon) with a cotton swab in the inner surface of denture, which was immediately placed in the mouth, and surplus gel was spat out. Patients of Group III made mouthwash with the solution of propolis $(5 \mathrm{~mL})$ during a minute and then spat out. All the treatments groups have used four daily applications, during 14 days. The patients were asked to maintain their usual regime for wearing their dentures. After a week the patients were reexamined to verify any intolerance to the medications and how their denture hygiene was. The treatment was given by another oral medicine examiner.

After the treatment the same first oral medicine examiner, in a double-blind way, evaluated all the patients of the three study groups for a second classification for denture stomatitis, new photographs, and a new swab of palatal mucosa, following the same protocol used before the treatments.

The glycolic extract of propolis applied in this research was formulated and provided by Fundação Ezequiel Dias, in Belo Horizonte, MG, Brazil. In vitro tests were done to establish the better concentration and the therapeutic efficacy 
TABLE 1: Quantitative evaluation of yeasts (CFUs) and clinical classification of denture stomatitis before and after the treatment with Miconazole gel $2 \%$.

\begin{tabular}{|c|c|c|c|c|c|c|}
\hline Patient & Age & Gender & $\begin{array}{c}N \text { CFUs }{ }^{*} \\
\text { Before treatment }\end{array}$ & $\begin{array}{c}N \text { CFUs }^{* *} \\
\text { After treatment }\end{array}$ & $\begin{array}{l}\text { Denture stomatitis } \\
\text { classification } \\
\text { Before treatment }\end{array}$ & $\begin{array}{l}\text { Denture stomatitis } \\
\text { classification } \\
\text { After treatment }^{* *}\end{array}$ \\
\hline 1 & 58 & $\mathrm{~F}$ & 20 & 1 & II & Cure \\
\hline 2 & 79 & M & 189 & 79 & III & 1 \\
\hline 3 & 49 & $\mathrm{~F}$ & 12 & 0 & I & Cure \\
\hline 4 & 66 & $\mathrm{~F}$ & 12 & 0 & II & I \\
\hline 5 & 69 & $\mathrm{~F}$ & 19 & 0 & I & Cure \\
\hline 6 & 73 & $\mathrm{~F}$ & 18 & 0 & I & Cure \\
\hline 7 & 72 & $\mathrm{~F}$ & 95 & 2 & I & Cure \\
\hline 8 & 73 & $\mathrm{~F}$ & 15 & 0 & III & I \\
\hline 9 & 66 & $\mathrm{~F}$ & 38 & 0 & II & I \\
\hline 10 & 65 & $\mathrm{~F}$ & 27 & 1 & II & II \\
\hline 11 & 60 & $\mathrm{~F}$ & 226 & 0 & I & I \\
\hline 12 & 61 & $\mathrm{~F}$ & 43 & 0 & I & I \\
\hline 13 & 27 & $\mathrm{~F}$ & 11 & 1 & III & I \\
\hline 14 & 74 & M & 62 & 0 & I & Cure \\
\hline 15 & 45 & M & 168 & 0 & III & I \\
\hline
\end{tabular}

${ }^{*}$ CFUs: colony-forming units.

**Newton's classification (type: $1 ; 2 ; 3$ ).

Clinical evaluation before and after treatment-Wilcoxon's test $P=0.0007$

Quantitative microbiological evaluation before and after treatment-Wilcoxon's test $P=0.0022$.

Mean age: $62.47 \pm 13.54$.

of the propylene glycol extract of Brazilian green propolis, according to the National Committee for Clinical Laboratory Standards [25].

2.4. Statistical Analysis. To compare the results of clinical classification of the denture stomatitis and the Candida spp. colonies number, before and after each treatment, Wilcoxon's test was applied. The Kruskall-Wallis's test was used to compare the efficacy among the three treatment groups (Biostat, 4.0). The considered significance level was $P<0.05$.

\section{Results}

Data of the interview showed that denture hygiene was done in a similar way by all denture wearers, including the 35 patients with clinical signals of denture stomatitis who were excluded from the study group, once they did not present positive results for Candida spp. All the 30 selected subjects with health palatal mucosa (15 denture users and 15 with natural teeth) had no growth in culture and any yeast observation at microscopy. They were chosen to attempt a comparison of Candida spp. number of colonies between individuals with health palatal mucosa and with denture stomatitis.

Among the study group patients $(n=45)$ the used time of the same denture varied from three months to 48 years. Systemic diseases were related by $82.6 \%$ of them, especially arterial hypertension (53.3\%); 77.3\% were using some medication, mainly antihypertensive (41.3\%).

The age of these patients was between 27 and 79 years old (mean age $60.76 \pm 11.34$ ). There were seven males $(15.5 \%)$ and 38 females $(84.4 \%)$. In the presumptive identification of Candida spp., only Candida albicans was isolated.

Tables 1, 2, and 3 show the results of the clinical aspects (based in the Newton's classification) and the microbiologic results (total count of CFUs), before and after the treatment with miconazole gel (Group I, Table 1) and with the two forms of propylene glycol Brazilian green propolis: gel (Group II, Table 2) and solution for mouthwash (Group III, Table 3).

The three treatments showed significant statistical results in the reduction or in the complete clinical remission of denture stomatitis and in the decrease or elimination of yeast count. No statistical differences in efficacy were seen among the three groups, either for reduction or remission of palatal erythema $(P=0.1069)$ or to reduction or elimination of CFUs $(P=0.9586)$.

Results of Tables 1, 2, and 3 showed that the number of CFUs was not related with the degree of clinical erythema severity, according to Newton's classification. All the patients who still presented denture stomatitis and some CFUs after treatments were maintained in use of their medications for more 14 days, following the same protocol. All denture wearers examined at baseline for this study $(n=85)$ were invited to an evaluation of their dentures in the Prosthesis Clinic of DOPUC Minas. 
TABLE 2: Quantitative evaluation of yeasts (CFUs) and clinical classification of denture stomatitis before and after the treatment with propylene glycol Brazilian green propolis gel $2.5 \%$.

\begin{tabular}{|c|c|c|c|c|c|c|}
\hline Patient & Age & Gender & $\begin{array}{c}\text { N CFUs }{ }^{*} \\
\text { Before treatment }\end{array}$ & $\begin{array}{c}N \text { CFUs }^{* *} \\
\text { After treatment }\end{array}$ & $\begin{array}{l}\text { Denture stomatitis } \\
\text { classification }^{* *} \\
\text { Before treatment }\end{array}$ & $\begin{array}{c}\text { Denture stomatitis } \\
\text { Classification }^{* *} \\
\text { After treatment }\end{array}$ \\
\hline 1 & 52 & $\mathrm{~F}$ & 64 & 0 & I & Cure \\
\hline 2 & 78 & $\mathrm{~F}$ & 78 & 1 & I & Cure \\
\hline 3 & 61 & M & 84 & 0 & II & Cure \\
\hline 4 & 68 & $\mathrm{~F}$ & 136 & 6 & I & I \\
\hline 5 & 30 & $\mathrm{~F}$ & 45 & 4 & II & II \\
\hline 6 & 58 & $\mathrm{~F}$ & 288 & 89 & II & I \\
\hline 7 & 78 & $\mathrm{~F}$ & 189 & 0 & II & I \\
\hline 8 & 72 & $\mathrm{~F}$ & 9 & 0 & III & Cure \\
\hline 9 & 59 & $\mathrm{~F}$ & 548 & 0 & III & I \\
\hline 10 & 66 & $\mathrm{~F}$ & 52 & 24 & II & I \\
\hline 11 & 50 & $\mathrm{~F}$ & 58 & 0 & I & Cure \\
\hline 12 & 46 & $\mathrm{~F}$ & 158 & 33 & II & I \\
\hline 13 & 45 & $\mathrm{~F}$ & 472 & 117 & III & I \\
\hline 14 & 53 & $\mathrm{~F}$ & 283 & 23 & III & I \\
\hline 15 & 50 & M & 47 & 0 & I & I \\
\hline
\end{tabular}

${ }^{*}$ CFUs: colony-forming units.

${ }^{* *}$ Newton's classification (type: $1 ; 2 ; 3$ ).

Clinical evaluation before and after treatment-Wilcoxon's test $P=0.0007$.

Quantitative microbiological evaluation before and after treatment-Wilcoxon's test $P=0.0022$.

Mean age: $57.73 \pm 13.24$.

TABLE 3: Quantitative evaluation of yeasts (CFUs) and clinical classification of denture stomatitis before and after the treatment with propylene glycol Brazilian green propolis $24 \%$ solution for mouthwash.

\begin{tabular}{|c|c|c|c|c|c|c|}
\hline Patient & Age & Gender & $\begin{array}{c}N \text { CFUs* } \\
\text { Before treatment }\end{array}$ & $\begin{array}{c}N \text { CFUs }^{* *} \\
\text { After treatment }\end{array}$ & $\begin{array}{l}\text { Denture stomatitis } \\
\text { classification } \\
\text { Before treatment }\end{array}$ & $\begin{array}{l}\text { Denture stomatitis } \\
\text { classification } \\
\text { After treatment }\end{array}$ \\
\hline 1 & 66 & $\mathrm{~F}$ & 105 & 0 & II & Cure \\
\hline 2 & 66 & M & 269 & 1 & III & Cure \\
\hline 3 & 60 & $\mathrm{~F}$ & 14 & 0 & II & I \\
\hline 4 & 67 & M & 18 & 0 & I & Cure \\
\hline 5 & 65 & $\mathrm{~F}$ & 12 & 0 & I & Cure \\
\hline 6 & 68 & $\mathrm{~F}$ & 18 & 0 & III & III \\
\hline 7 & 63 & $\mathrm{~F}$ & 226 & 1 & I & Cure \\
\hline 8 & 65 & $\mathrm{~F}$ & 22 & 1 & III & III \\
\hline 9 & 46 & $\mathrm{~F}$ & 19 & 0 & I & I \\
\hline 10 & 60 & $\mathrm{~F}$ & 19 & 0 & III & III \\
\hline 11 & 60 & $\mathrm{~F}$ & 17 & 0 & I & Cure \\
\hline 12 & 61 & $\mathrm{~F}$ & 28 & 0 & I & Cure \\
\hline 13 & 65 & $\mathrm{~F}$ & 12 & 0 & I & Cure \\
\hline 14 & 63 & $\mathrm{~F}$ & 296 & 0 & III & III \\
\hline 15 & 56 & $\mathrm{~F}$ & 113 & 0 & I & Cure \\
\hline
\end{tabular}

${ }^{*}$ CFUs: colony-forming units.

${ }^{* *}$ Newton's classification (type: $1 ; 2 ; 3$ ).

Clinical evaluation before and after treatment-Wilcoxon's test $P=0.0007$.

Quantitative microbiological evaluation before and after treatment-Wilcoxon's test $P=0.00077$.

Mean age: $62.06 \pm 5.52$. 


\section{Discussion}

One of the limitations of the clinical trials is the impossibility of controlling the medicaments correct use by patients at home. Despite this limitation, the results found in the present study showed that all the products used presented efficacy for denture stomatitis clinical cure or reduction and for number of Candida albicans colonies in culture elimination or reduction. Few double-blinded, controlled-randomized clinical-trials studies for topical treatment comparison of Candida-associated denture stomatitis between Brazilian green propolis and current medicinal treatment generally done with topical well-known antifungal as miconazole gel $[2,5]$ have been reported. According to our best knowledge, this is the first study which reports the use of $2.5 \%$ propylene glycol extract of Brazilian green propolis for the treatment of Candida-associated denture stomatitis, comparing clinical erythema and count of CFUs before and after treatment and that established the best safety Brazilian green propolis concentration through Candida inhibition test and that made Candida spp. identification.

Propolis is considered a safe natural bee product and has been extensively used in folk medicine since early times for its pharmaceutical properties and its antiviral, antibacterial, and antifungal properties have been demonstrated in a number of investigations $[12,14,15]$. Only few cases of allergy to propolis were reported, and, up to the present moment, there have been no description of Brazilian green propolis side effects $[19,21]$. Systemic antifungals as fluconazole are expensive, and the topical ones, such as nystatin and miconazole, have some side effects as informed in their medical bulls. Due to the increasing resistance to fluconazole and the limited power of action and toxicity of some antifungal drugs, new alternatives in the treatment of denture stomatitis are welcome [26].

Good results using ethanolic [11, 23] and propylene glycol vehicles of Brazilian propolis in denture stomatitis treatment [27] have been reported.

Propylene glycol is a humectant vehicle of common use in pharmacologic formulations, and it is an oral mucosa nonirritant product. In this pilot study propylene glycol extract of Brazilian green propolis was well accepted by the patients, and its nonirritant action makes this formulation reliable. Medications with ethanol vehicle could induce irritation and oral erythema that could modify or disguise the results, if denture stomatitis is still present after the treatment [19]. Patients who received mouthwash propolis form were the most pleased in relation to the taste and the easy way of their treatment in this study.

For the three groups, there was statistically significant yeast cells count suppression or decrease of the palatal mucosa inflammation, after treatment. However, there was no erythema complete remission or total colonies elimination for all patients, neither for the ones who received miconazole nor for the ones who received propolis. Studies with similar methodology using miconazole gel $[2,25]$ and ethanolic extract of Brazilian green propolis [23] showed similar results. Nevertheless, Santos et al. [27] reported clinical erythema total remission either by using miconazole gel or
Brazilian green propolis gel. There was a female prevalence in this study as may be expected from the epidemiology of this condition [28].

An association among CFUs number and palatal erythema severity was expected. In spite of that, there was persistent denture stomatitis in patients who presented decrease or absence of Candida spp. colonies after treatment, in the three groups evaluated. On the other hand, some patients had a great number of colonies and less erythema after their treatment. These results can be explained by other predisposing factors as systemic diseases, high consumption of saccharose and denture alterations. This could increase CFUs number, regardless candidiasis presence in those patients. Budtz-Jörgensen and Carlino [5] already described no apparent correlation among extensive mycological events when compared to clinical parameters [9].

The lack of CFUs number in culture of 35 out of 85 denture wearers with palatal mucosa erythema, assessed at the start of the study, also reinforced the multifactorial etiology of denture stomatitis. Denture stomatitis presence with or without growth of Candida spp. colonies found suggests the need of meticulous investigation in medical history of patients with this lesion to identify associated risk factors. This study results also suggest that microbiological tests for Candida spp. detection are needed before starting any kind of antifungal therapy. This conduct avoids useless antifungal therapy. According to Barbeau et al. [6], some well-known risk factors associated with denture stomatitis are prosthesis with old age, maladjustments, instability, broken, worn during sleep, deficient in hygiene, and worn by patients who have some systemic diseases or smoking. However, Candida albicans, found here in all the 45 patients of the treatment groups, has been considered as an important factor in the etiology of denture stomatitis $[1-3,5,7,10]$.

The presumptive identification of $C$. albicans is mainly obtained through germ-tube test. Lacaz et al. [29] reported that C. dubliniensis also makes germ tube, in the same conditions. C. dubliniensis is more found in immunological depressed patients, and C. albicans is generally associated with denture stomatitis. This data points out the hypothesis that, in this study, the positive germ-tube test showed the presence of C. albicans.

C. albicans is part of the oral microbiota [30]; however, there was no yeast growth of Candida spp. in the swabs of the 30 patients with health palatal mucosa in this study. This fact suggests that either palatal mucosa is not a Candida common habitat in normal conditions or it is difficult to obtain Candida samples in the palate.

\section{Conclusions}

The overall results of this randomized clinical trial showed that propylene glycol Brazilian green propolis has an antifungal activity similar to miconazole, in the $C$. albicans colonies decrease and in the erythema reduction of patients with Candida-associated denture stomatitis. Brazilian green propolis that has antifungal properties, is a safe, affordable, and natural product without well-known side effects up to 
now. Thus, it can be a good alternative in Candida-associated denture stomatitis treatment, especially for public health.

\section{Acknowledgment}

This study was supported by grants from Fundação de Amparo à Pesquisa do Estado de Minas Gerais (FAPEMIG). The authors are grateful to Fundação Ezequiel Dias (FUNED), Belo Horizonte, MG, Brazil, for formulating and providing the glycolic extract of Brazilian green propolis applied in this research and for the in vitro tests.

\section{References}

[1] E. Budtz-Jörgensen, A. Stenderup, and M. Grabowski, "An epidemiologic study of yeasts in elderly denture wearers," Community Dentistry and Oral Epidemiology, vol. 3, no. 3, pp. 115-119, 1975.

[2] R. Könsberg and T. Axéll, "Treatment of Candida-infected denture stomatitis with a miconazole lacquer," Oral Surgery, Oral Medicine, Oral Pathology, vol. 78, no. 3, pp. 306-311, 1994.

[3] C. Salerno, M. Pascale, M. Contaldo et al., "Candida-associated denture stomatitis," Medicina Oral Patologia Oral y Cirugia Bucal, vol. 16, pp. e139-e143, 2011.

[4] C. S. Farah, N. Lynch, and M. J. McCullough, "Oral fungal infections: an update for the general practitioner," Australian Dental Journal, vol. 55, pp. 48-54, 2010.

[5] E. Budtz-Jörgensen and P. Carlino, "A miconazole lacquer in the treatment of Candida-associated denture stomatitis," Mycoses, vol. 37, no. 3-4, pp. 131-135, 1994.

[6] J. Barbeau, J. Séguin, J. P. Goulet et al., "Reassessing the presence of Candida albicans in denture-related stomatitis," Oral Surgery, Oral Medicine, Oral Pathology, Oral Radiology, and Endodontology, vol. 1, pp. 51-59, 2003.

[7] K. Zomorodian, N. N. Haghighi, N. Rajaee et al., "Assessment of Candida species colonization and denture-related stomatitis in complete denture wearers," Medical Mycology, vol. 49, no. 2, pp. 208-211, 2011.

[8] L. J. Cross, J. Bagg, D. Wray, and T. Aitchison, "A comparison of fluconazole and itraconazole in the management of denture stomatitis: a pilot study," Journal of Dentistry, vol. 26, no. 8, pp. 657-664, 1998.

[9] E. Budtz-Jörgensen and T. Lombardi, "Antifungal therapy in the oral cavity," Periodontology 2000, vol. 10, no. 1, pp. 89-106, 1996.

[10] B. C. Webb, C. J. Thomas, M. D. P. Willcox, D. W. S. Harty, and K. W. Knox, "Candida-associated denture stomatitis. Aetiology and management: a review. Part 3. Treatment of oral candidosis," Australian Dental Journal, vol. 43, no. 4, pp. 244-249, 1998.

[11] V. R. Santos, F. J. G. S. Pimenta, M. C. F. Aguiar, M. A. V. Do Carmo, M. D. Naves, and R. A. Mesquita, "Oral candidiasis treatment with Brazilian ethanol propolis extract," Phytotherapy Research, vol. 19, no. 7, pp. 652-654, 2005.

[12] M. C. Marcucci, "Propolis: chemical composition, biological properties and therapeutic activity," Apidologie, vol. 26, no. 2, pp. 83-99, 1995.

[13] A. Kujumgiev, I. Tsvetkova, Y. Serkedjieva, V. Bankova, R. Christov, and S. Popov, "Antibacterial, antifungal and antiviral activity of propolis of different geographic origin," Journal of Ethnopharmacology, vol. 64, no. 3, pp. 235-240, 1999.
[14] S. Stepanović, N. Antić, I. Dakić, and M. Švabić-Vlahović, "In vitro antimicrobial activity of propolis and synergism between propolis and antimicrobial drugs," Microbiological Research, vol. 158, no. 4, pp. 353-357, 2003.

[15] J. Metzner, E. M. Schneidewind, and E. Friedrich, "On the effects of propolis and pinocembrin on blastomyces," Pharmazie, vol. 32, no. 11, p. 730, 1977.

[16] V. S. Bankova, R. Chistovi, A. Kujumgiev et al., "Chemical composition and antibacterial activity of Brazilain propolis," Zeitschrift für Naturforschung, vol. 50, pp. 167-172, 1995.

[17] K. Salomão, A. P. Dantas, C. M. Borba et al., "Chemical composition and microbicidal activity of extracts from Brazilian and Bulgarian propolis," Letters in Applied Microbiology, vol. 38, no. 2, pp. 87-92, 2004.

[18] A. C. H. F. Sawaya, A. M. Palma, F. M. Caetano et al., "Comparative study of in vitro methods used to analyse the activity of propolis extracts with different compositions against species of Candida," Letters in Applied Microbiology, vol. 35, no. 3, pp. 203-207, 2002.

[19] E. C. Almeida and H. Menezes, "Anti-Inflammatory activity of propolis exctracts: a review," Journal of Venomous Animals and Toxins, vol. 8, pp. 191-212, 2002.

[20] A. H. Banskota, Y. Tezuka, and S. Kadota, "Recent progress in pharmacological research of propolis," Phytotherapy Research, vol. 15, no. 7, pp. 561-571, 2001.

[21] J. M. Sforcin, E. L. B. Novelli, and S. R. C. Funari, "Seasonal effect of Brazilian propolis on seric biochemical variables," Journal of Venomous Animals and Toxins, vol. 8, pp. 244-254, 2002.

[22] A. Garedew, E. Schmolz, and I. Lamprecht, "Microbiological and calorimetric investigations on the antimicrobial actions of different propolis extracts: an in vitro approach," Thermochimica Acta, vol. 422, no. 1-2, pp. 115-124, 2004.

[23] C. Ota, C. Unterkircher, V. Fantinato, and M. T. Shimizu, "Antifungal activity of propolis on different species of Candida," Mycoses, vol. 44, no. 9-10, pp. 375-378, 2001.

[24] A. V. Newton, "Denture sore mouth: a possible aetiology," British Dental Journal, vol. 112, pp. 357-360, 1962.

[25] NCCLS-National Committee for Clinical Laboratory Standards, "Método de Referência para testes de diluição em caldo para determinação da sensibilidade de leveduras à terapia antifúngica; norma aprovada-segunda edição," NCCLS Document M27-A2, 2003.

[26] M. Amanlou, J. M. Beitollahi, S. Abdollahzadeh, and Z. Tohidast-Ekrad, "Miconazole gel compared with Zataria multiflora Boiss. gel in the treatment of denture stomatitis," Phytotherapy Research, vol. 20, no. 11, pp. 966-969, 2006.

[27] V. R. Santos, R. T. Gomes, R. A. De Mesquita et al., "Efficacy of brazilian propolis gel for the management of denture stomatitis: a pilot study," Phytotherapy Research, vol. 22, no. 11, pp. 15441547, 2008.

[28] E. Budtz-Jörgensen, "Denture stomatitis, or candidiasis in denture wearers," Le Chirurgien-dentiste de France, vol. 44, no. 196, pp. 45-51, 1974.

[29] C. S. Lacaz, E. Porto, J. E. C. Martins et al., "Leveduras profundas, com especial referência à infecções bucais," in Tratado De Micologia Médica, pp. 618-638, Sarvier, São Paulo, Brazil, 1st edition, 2002.

[30] G. Pardi, E. I. Cardozo, M. Perrone et al., "Detección de espécies de Candida em casos de recidiva de pacientes com Estomatitis Sub-Protésica, medicados com Miconazol Jalea oral," Acta Odontológica Venezolana, vol. 41, pp. 3-17, 2003. 


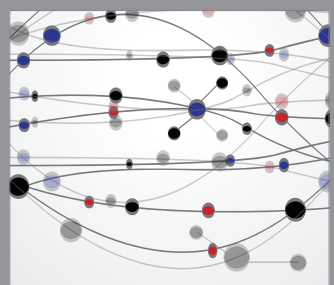

The Scientific World Journal
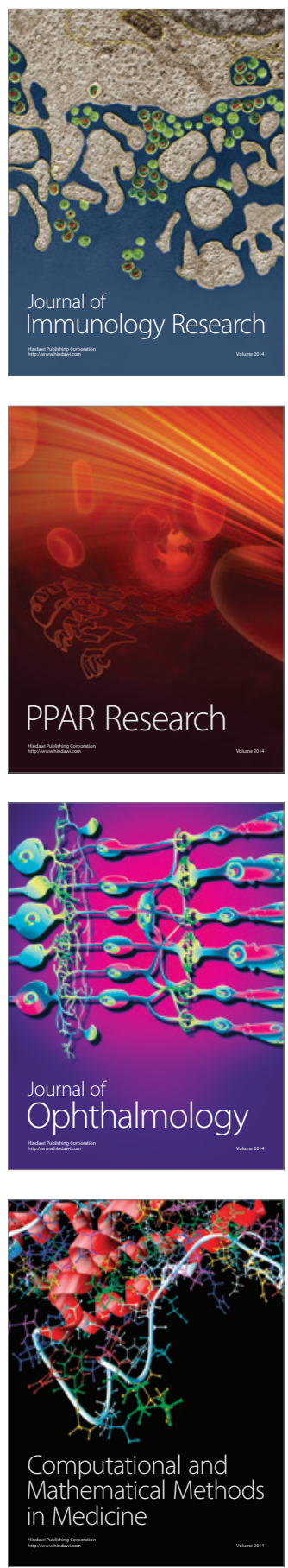

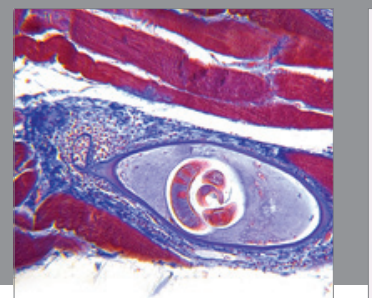

Gastroenterology

Research and Practice
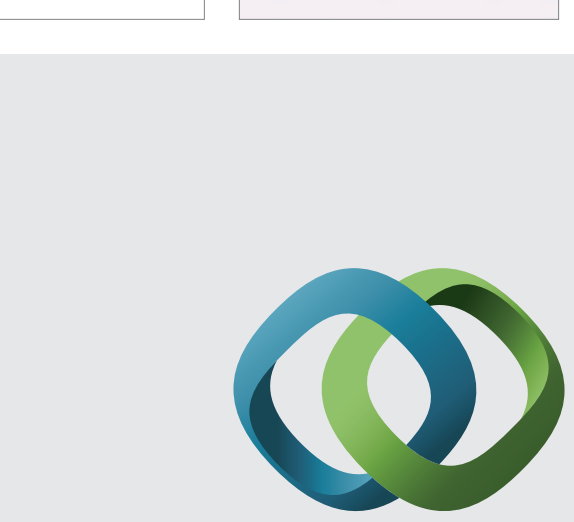

\section{Hindawi}

Submit your manuscripts at

http://www.hindawi.com
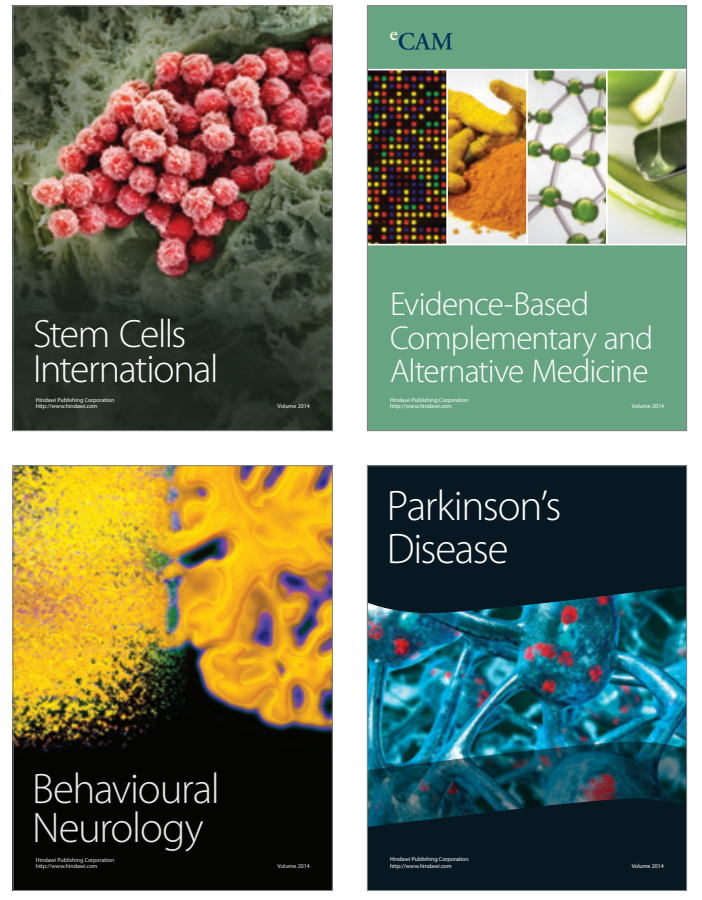
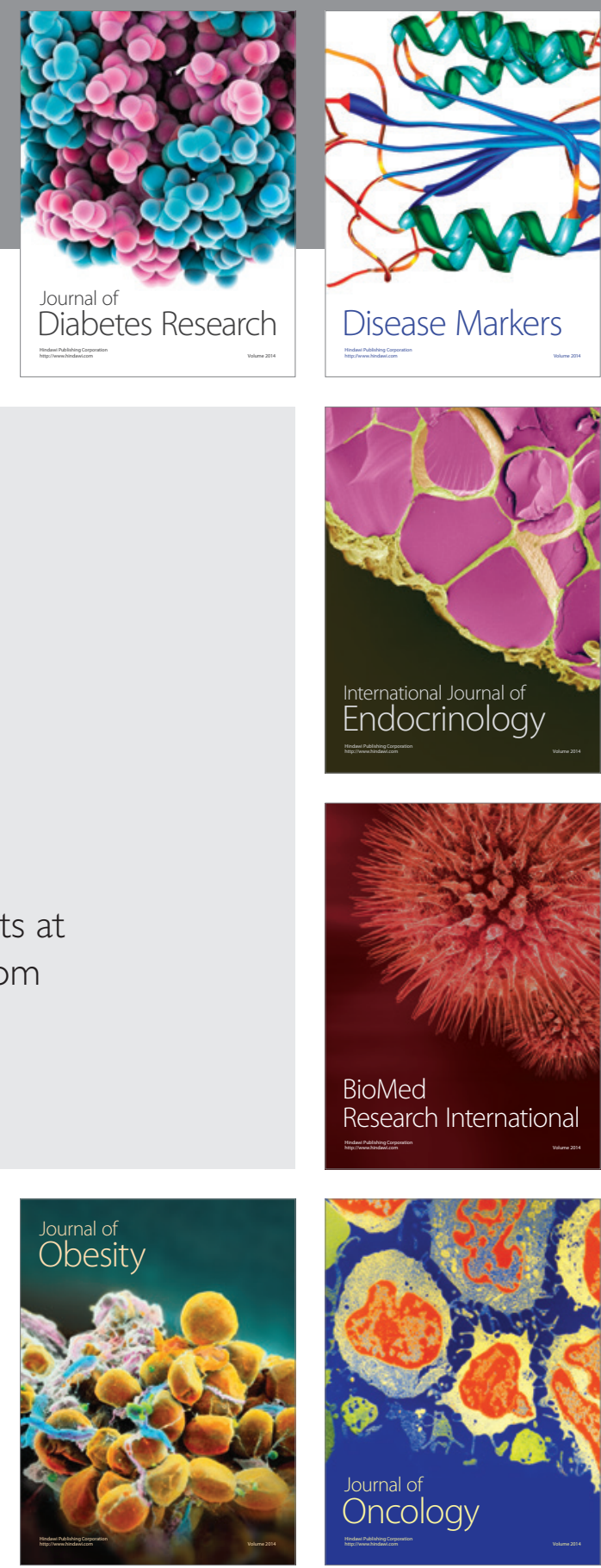

Disease Markers
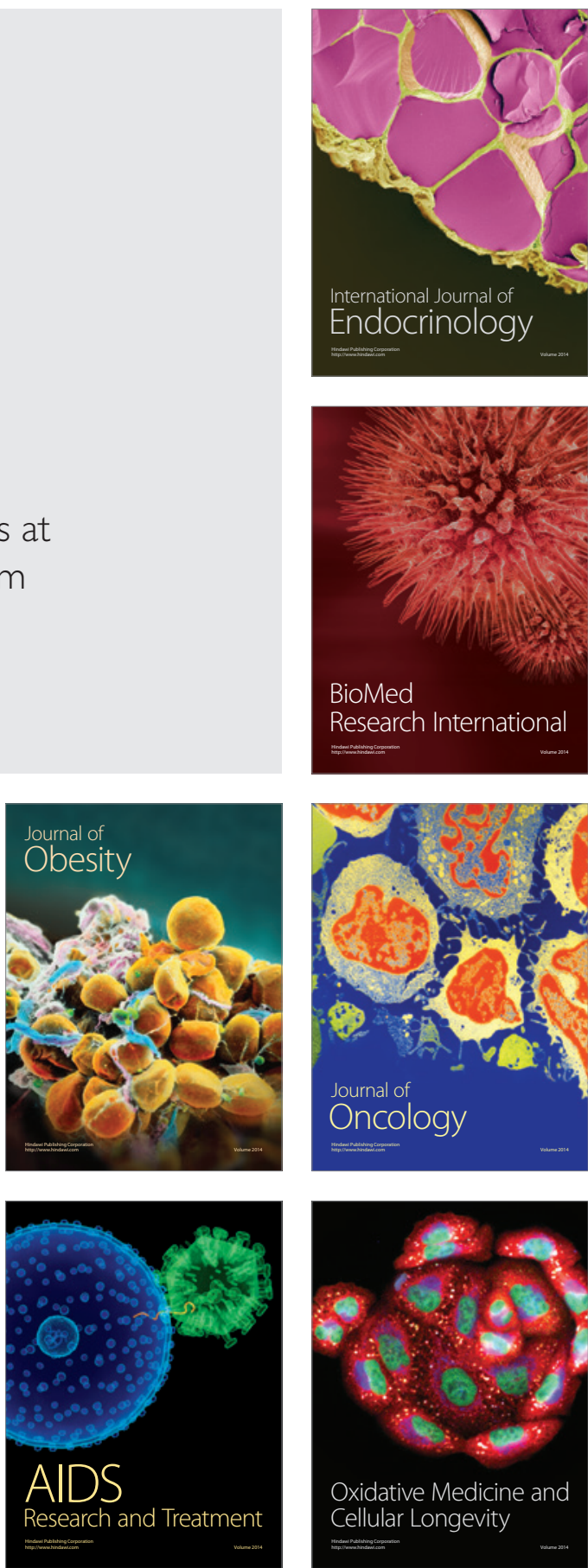